\title{
Calcium Channel Blocker Toxicity in a Cirrhotic Patient
}

\author{
Panagis Galiatsatos*, Dachelle Johnson, Ryan E Childers, Deeptankar Demazumder and Sammy Zakaria
}

Department of Medicine, Johns Hopkins Bayview Medical Center, Johns Hopkins University School of Medicine, Baltimore, USA

\begin{abstract}
Objective

To report a case of profound bradycardia as a result of verapamil toxicity due to impaired metabolism in a cirrhotic patient.

\section{Case report}

A 57 year old man with cirrhosis presented with weakness and syncope and a heart rate of twenty beats per minute $(\mathrm{bpm})$. Despite treatment with transcutaneous cardiac pacing, he developed a systole and required eight minutes of cardiopulmonary resuscitation before circulation was restored. After reviewing his medication list verapamil toxicity was suspected as the etiology for his cardiovascular collapse because of the drug's poor metabolic clearance in hepatic dysfunction. He was treated for calcium channel blocker toxicity, with calcium, insulin and dextrose infusions. By the seventh day, his blood pressure and heart rate were stable without invasive interventions However, his liver was unable to recover from the initial shock, leading to the patient's death.
\end{abstract}

\section{Discussion}

Calcium Channel Blocker (CCB) toxicity is associated with significant morbidity and mortality and is often diagnosed at the time of presentation (e.g. history of overdose). Treatment options include calcium infusion, which can lead to improvements in conduction, inotropy, and blood pressure; and high-dose insulin, which improves myocardial metabolism. These therapies were implemented in the patient, leading to hemodynamic stability, even in the setting of cirrhosis.

\section{Conclusion}

Caution is warranted when prescribing calcium channel blockers, such as verapamil, to patients with cirrhosis, since hepatic clearance will most likely be impaired, and may be associated with adverse events. If cirrhotic patients develop CCB toxicity, management is difficult, with few reports of specific treatment strategies.

Keywords: Calcium channel blockers; Toxicity; Calcium; Insulin; Cirrhosis

\section{Introduction}

Calcium Channel Blockers (CCB) are a versatile and popular class of drugs prescribed to treat hypertension, arrhythmias, and ischemic heart disease [1-3]. Verapamil, an inhibitor of the hepatic Cytochrome P450 (CYP) gene CYP3A4, is a nondihydropyridine calcium channel blocker, and is available in immediate or extended release formulations. In most patients with normal hepatic clearance, caution is advised when doses greater than 400-480 mg per day are used [4-6], because over-suppression of calcium flow can lead to severe cardiovascular compromise or collapse [7]. Consequently, CCBs are responsible for $16 \%$ of cardiovascular drug toxic exposures and $38-48 \%$ of all deaths $[6,7]$. Adverse effects are due to exaggerated calcium channel blockade, since CCBs interrupt the flow of calcium through L-type voltagegated calcium channels. This disruption of calcium flow into cardiac myocytes inhibits the release of more calcium from the sarcoplasmic reticulum, causing a decline in cardiac contraction and heart rate [8]. Since L-type channels increase vascular smooth muscle tone, CCBs can also result in vasodilatations [7].

In patients with impaired hepatic clearance, the use of verapamil or other CCBs have not been thoroughly investigated despite the common use of these agents. This is especially important since the liver metabolizes CCBs, with an extensive first-pass effect via multiple CYP genes. Cirrhosis, a process of progressive hepatic fibrosis with distortion of the hepatic architecture and formation of regenerative nodules [9], is a form of impaired hepatic clearance. Despite the high prevalence of cirrhosis, there are few reports of verapamil toxicity in this population $[10,11]$. In cirrhotic patients chronically taking CCBs, there are even fewer reports, with no descriptions in the last twenty years [12]. For these reasons, we describe a patient with liver disease who recently developed catastrophic cardiovascular complications of CCB toxicity, leading to his subsequent death. We also review conventional CCB toxicity management and discuss how this management is challenged in the setting of cirrhosis.

\section{Case Presentation}

A 57-year old man presented with weakness and fatigue. He had a long history for hypertension, cirrhosis due to hepatitis $\mathrm{C}$, and radiographic evidence concerning for hepatocellular cancer. He quit smoking two months prior to admission after smoking for 40 years, but did not drink alcohol or use intravenous drugs; in addition, he had

*Corresponding author: Panagis Galiatsatos, Department of Medicine, Johns Hopkins Bayview Medical Center, 4940 Eastern Avenue, Baltimore, USA, Tel: 410 550-0526; Fax: 410-550-1183; E-mail: pgaliat1@jhmi.edu

Received January 17, 2013; Accepted March 07, 2013; Published March 09 2013

Citation: Galiatsatos P, Johnson D, Childers RE, Demazumder D, Zakaria S (2013) Calcium Channel Blocker Toxicity in a Cirrhotic Patient. Cardiol Pharmacol 2: 106. doi:10.4172/2329-6607.1000106

Copyright: (C) 2013 Galiatsatos P, et al. This is an open-access article distributed under the terms of the Creative Commons Attribution License, which permits unrestricted use, distribution, and reproduction in any medium, provided the original author and source are credited. 
a strong family history for premature coronary and peripheral arterial disease. His baseline characteristics are presented in (Table 1), provided from an outpatient clinic visit one month prior to admission. At that time, he appeared to have well compensated cirrhosis, without ascites, edema, or encephalopathy. However, a hepatic lesion was noted on a hepatic ultrasound consistent with hepatocellular carcinoma; therefore, the visit served as the initiation of the transplant evaluation process. Also, his blood pressure was elevated, so the dosage of his verapamil, a medication he has taken for eight months, was increased from $120 \mathrm{mg}$ to $240 \mathrm{mg}$.

En route to the hospital, the patient developed profound bradycardia with a pulse of 20 beats per minute (bpm) that required cardiac transcutaneous pacing. On arrival to the hospital, his temperature was $37.5^{\circ} \mathrm{C}$, blood pressure $80 / 47 \mathrm{mmHg}$, and pulse 80 $\mathrm{bpm}$. An attempt was made to place a transvenous cardiac pacer but was unsuccessful. He then developed a systole, and required eight minutes of cardiopulmonary resuscitation before regaining a pulse. He was endotracheally incubated for airway protection, transcutaneous pacing was resumed, and he was infused with intravenous fluids and norepinephrine. An electrocardiogram (ECG) revealed accelerated junction rhythm with occasional paced beats (Figure 1A). Laboratory data were notable for hyponatremia, hyperkalemia and metabolic acidosis (Table 2) but there were no signs of toxin ingestion, infection, or cardiac enzyme elevations.

The patient was then taken to the cardiac intensive care unit. Physical examination revealed constricted pupils, mechanical ventilation sounds in both lungs, diminished heart sounds due to transcutaneous pacing noise, a distended abdomen with no abdominal sounds, and erythematous and mildly edematous extremities. A computed tomogram of the chest and abdomen was notable for signs of cirrhosis and ileus, and a transthoracic echocardiogram revealed mild

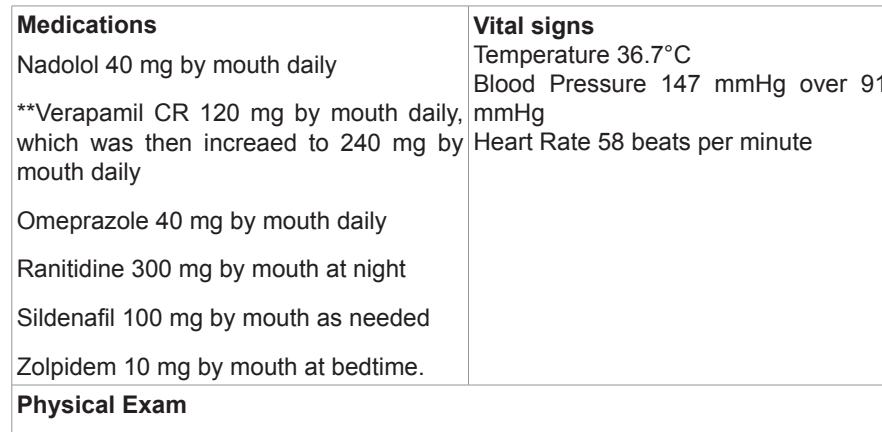

"The patient is alert and oriented times three with no evidence of confusion. The sclera are non-icteric.

Pulmonary exam reveals clear lung sounds with no rhonchi, wheezing or rales. Cardiac exam revealed a baseline systolic ejection murmur, grade 2 out of 6 , heard across the precoridium. Abdominal exam revealed a soft and non-tender abdomen with no ascites and no palpable spleen; his liver was $2 \mathrm{~cm}$ below the costal margin of the epigastrium. There was no edema of the extremities".

Co-morbidities

Hypertension: managed for two years with nadolol and amlodipine; switched to verapamil from amlodipine eight months prior to hospitalization due to ankle swelling.

Chronic Hepatitis C Infection.

Cirrhosis with MELD Score 8

Hepatocellular carcinoma screening: recently found hepatic lesion; alpha fetal protein level measured at $39 \mathrm{ng} / \mathrm{mL}$ (rising from $23 \mathrm{ng} / \mathrm{mL}$ one year prior).

Table 1: Baseline characteristics of patient, provided by clinic visit one month prior to hospitalization. global left ventricular hypokinesis with an estimated ejection fraction of $40-45 \%$.

He was presumptively treated for calcium channel blocker toxicity with high dose intravenous calcium therapy along with dextrose and insulin infusions. He received intravenous (IV) calcium gluconate $0.3-$ $1.2 \mathrm{~g}$ hourly $(0.02 \mathrm{meq} / \mathrm{kg} / \mathrm{h}-0.06 \mathrm{meq} / \mathrm{kg} / \mathrm{h})$ for six consecutive days, with intermittent 1 and $2 \mathrm{~g}$ doses thereafter. Initially, he was infused with 1 unit of insulin hourly along with 10 percent dextrose in water, ranging from 25 to $75 \mathrm{ml}$ hourly $(0.03 \mathrm{~g} / \mathrm{kg} / \mathrm{h}-0.09 \mathrm{~g} / \mathrm{kg} / \mathrm{h})$. Thereafter, he required intermittent IV doses of $50 \mathrm{ml}$ of 50 percent dextrose in water $(25 \mathrm{~g})$ and $1-8$ units of insulin hourly $(0.01 \mathrm{unit} / \mathrm{kg} / \mathrm{h}-0.1 \mathrm{unit} /$ $\mathrm{kg} / \mathrm{h}$ ) titrated to a blood glucose level of $140-180 \mathrm{mg} / \mathrm{dL}$. He also required renal replacement therapy, administered via continuous venovenous hemodialysis (CVVHD) for anuria likely due to ischemic acute tubular necrosis. Within one day, all of his metabolic abnormalities normalized, and a rhythm strip revealed atrial fibrillation (Figure 1B). After four days, his ileus resolved, and he no longer required intermittent transcutaneous cardiac pacing since his rhythm reverted to sinus rhythm (Figure 1C). However, it was not until the seventh day that calcium, insulin and dextrose infusions were successfully weaned off and the patient maintained normal sinus rhythm with stable blood pressures. In addition, he no longer required mechanical ventilation or hemodialysis.

Despite improvements in his cardiovascular status, he continued to have worsening liver failure, with a peak AST greater than 20,000 U/L, ALT at $4729 \mathrm{U} / \mathrm{L}$, and alkaline phosphatase level of $204 \mathrm{U} / \mathrm{L}$. He subsequently developed disseminated intravascular coagulation on the seventh day. His family made the decision to transition him to comfort measures and the patient died the next day. On that same day, his serum verapamil level (obtained on the second day of admission) returned from the outside laboratory and was $190 \mathrm{ng} / \mathrm{mL}$ (therapeutic range is $70-350 \mathrm{ng} / \mathrm{mL}$ ).

\section{Discussion}

\section{Manifestations of CCB toxicity in patients with cirrhosis}

The most common manifestations of CCB toxicity are bradycardia and hypotension - essentially pronounced manifestations of their therapeutic actions $[7,8]$. As a result, patients can develop a systole, complete heart block with associated junctional escape beats or rhythm, or slow ventricular rhythms $[13,14]$. In addition, non-cardiovascular symptoms can occur, including weakness, lightheadedness, or depressed mental status. Rarely, patients can develop paralytic ileus (due to calcium's action on smooth muscle), bowel infarction, stroke, or pulmonary edema $[8,15,16]$. Finally, CCB toxicity can cause acidosis and hyperglycemia, because of calcium channel receptor blockade on

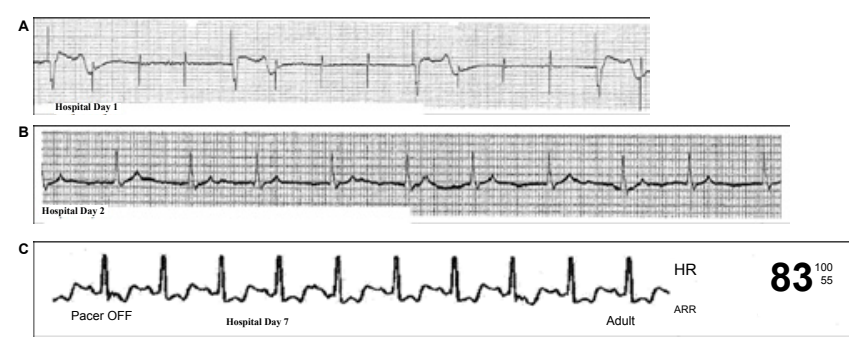

Figure 1: A. Accelerated junctional rhythm with occasional paced beats. Hospital Day 1.

B. Atrial fibrillation after initiation of intravenous calcium \& insulin. Hospital Day 2. C. Normal sinus rhythm. Hospital Day 7 . 


\section{Complete Metabolic Panel}

\section{Day 1 Day 2}

Sodium $135 \mathrm{mEq} / \mathrm{L} 127 \mathrm{mEq} / \mathrm{L}$

Potassium $6.7 \mathrm{mEq} / \mathrm{L} 5.9 \mathrm{mEq} / \mathrm{L}$

Chloride $105 \mathrm{mEq} / \mathrm{L} 88 \mathrm{mEq} / \mathrm{L}$

Bicarbonate $12 \mathrm{mEq} / \mathrm{L} 14 \mathrm{mEq} / \mathrm{L}$

Blood urea nitrogen $43 \mathrm{mg} / \mathrm{dL} 51 \mathrm{mg} / \mathrm{dL}$

Creatinine $2.5 \mathrm{mg} / \mathrm{dL} 4.2 \mathrm{mg} / \mathrm{dL}$

\section{Aspartate transaminase $145 \mathrm{IU} / \mathrm{L} 9469$ Additional data}

IU/L $\quad$ Day 1 Day 2

Alanine transaminase $176 \mathrm{IU} / \mathrm{L} 2809$ Lactic Acid $10.5 \mathrm{mmol} / \mathrm{L} 7.2 \mathrm{mmol} / \mathrm{L}$

IU/L Ammonia $105 \mathrm{mg} / \mathrm{dL} 73 \mathrm{mg} / \mathrm{dL}$

Alkaline phosphatase $173 \mathrm{IU} / \mathrm{L} 153 \mathrm{IU} / \mathrm{L}$ Troponin < $0.02 \mathrm{ng} / \mathrm{mL} 2.50 \mathrm{ng} / \mathrm{mL}$

Total Bilirubin $2.2 \mathrm{mg} / \mathrm{dL} 3.2 \mathrm{IU} / \mathrm{L} \quad$ Total Creatinine $35 \mathrm{U} / \mathrm{L} 679 \mathrm{U} / \mathrm{L}$

Albumin $3.1 \mathrm{~g} / \mathrm{dL} 2.3 \mathrm{~g} / \mathrm{dL}$

Total Protein $7.4 \mathrm{~g} / \mathrm{dL} 5.3 \mathrm{~g} / \mathrm{dL}$

INR 1.22 .2

\section{Complete Blood Count}

Day 1 Day 2

White blood cells 14380 cells per liter 24090 cells per liter

Hemoglobin $13.1 \mathrm{~g} / \mathrm{dL} 12.6 \mathrm{~g} / \mathrm{dL}$

Platelets 196 cells per liter 111 cells per liter Hematocrit $40.9 \% 39.0 \%$

\section{Microbial data}

Blood cultures

Obtained 4 hours on arrival Negative

Obtained 17 hours on arrival Negative

Urine cultures

Obtained 4 hours on arrival Negative

HIV Antibody test Negative

Table 2: Laboratory findings drawn on day 1 and day 2 of hospital admission.

the islets of Langerhans $[7,17]$.

CCB toxicity effects on cardiovascular and non-cardiovascular systems can have even more severe consequences in a patient with cirrhosis. Cirrhotic patients have elevated portal circulatory pressures and tend to have hyperdynamic vasodilated systemic cardio vasculatures, leading to low baseline blood pressures and high cardiac output $[18,19]$. In addition, cirrhotic have low intravascular volume, due to impaired synthesis of albumin and other proteins, resulting in a low intravascular osmotic pressure. Autonomic dysfunction is also common, leading to impaired myocardial contractility in response to orthostatic or vasoconstrictors $[18,20,21]$. Finally, cirrhosis is associated with adrenal insufficiency, leading to a decrease in cortisoldriven responses and hemodynamic instability (the hepato-adrenal syndrome) [22-24]. The combination of these factors can make the management of cirrhotic patients with a critical illness, such as $\mathrm{CCB}$ toxicity, very challenging.

\section{Case uncertainties}

Toxicity likely occurred due to the patient's calcium channel blocker dose increase in the setting of a new hepatic lesion, which may have further worsened the underlying hepatic dysfunction due to cirrhosis. Verapamil metabolism is exquisitely sensitive to liver dysfunction, as it undergoes first pass elimination when given orally and is metabolized by the liver through the CYP $3 \mathrm{~A} 4$ pathway $[25,26]$. This route of metabolism is completely altered in patients with cirrhosis due to reduced amount of functioning hepatocytes and extrahepatic shunting of blood supply, thus bypassing any functional hepatocytes. As a result, the bioavailability of oral immediate release verapamil increased to a mean $53 \%$ in patients with liver cirrhosis compared to 20 to $30 \%$ in healthy patients [27]. In addition, drug clearance was reduced to $20 \%$ of normal, with a steady state plasma concentration that was five times the normal value when given orally, along with a greater volume of distribution $[27,28]$. However, pharmacokinetic modeling for sustained release verapamil in patients with cirrhosis does not exist.
We are limited by a lack of an obvious history of overdose and by the normal verapamil level obtained on the second day of admission. The random verapamil level must be interpreted cautiously, since the timing of his last dose was unknown and an accurate pharmacokinetic model does not exist. In addition, verapamil levels can be misleading since patients can be without complications at high levels and others can be toxic at normal levels [28]. Despite these limitations, the Naranjo probability scale revealed a probable relationship between his symptoms and verapamil administration [29]. Points were given for previous conclusive reports of this reaction, temporal relationship between drug administration and adverse event, improvement upon drug discontinuation and administration of an antagonist, worsening upon dose increase, and confirmation of adverse event by objective evidence (Table 3) [29]

We also considered nadolol toxicity, since it can present in a similar fashion as CCB toxicity; however, we thought it was unlikely for two reasons: the patient was placed on CVVHD, which should clear nadolol [30], and temporary cessation of insulin and calcium therapy led to reoccurrence of hypotension and bradycardia, which would not occur with beta blocker toxicity. In any case, no alternative diagnoses were satisfactory to explain the patient's presentation (such as shock), and he did show clinical improvement with treatments for CCB toxicity. Interestingly his calcium, dextrose, and insulin dosing requirements were much lower but were required for a longer period of time when compared to previous published regimens for CCB toxicity. This could be due to the pharmacologic differences between sustained versus immediate release products. Unfortunately, despite successful treatment of CCB toxicity, his ultimate demise, even after his vital signs were stabilized, was likely attributed to a shocked liver on presentation that never recovered, ultimately leading to fulminant liver failure.

\section{CCB toxicity management}

As is in the case, management of severe CCB toxicity is difficult. In general, CCBs are not dialyzable, since they are highly protein bound

\begin{tabular}{|c|c|c|c|}
\hline Naranjo scale* & Yes & No & $\begin{array}{l}\text { Do not know or } \\
\text { not performed. }\end{array}$ \\
\hline $\begin{array}{l}\text { 1. Are there previous conclusive } \\
\text { reports on this reaction? }\end{array}$ & +1 & & \\
\hline $\begin{array}{l}\text { 2. Did the adverse events appear after } \\
\text { the suspected drug was given? }\end{array}$ & +2 & & \\
\hline $\begin{array}{l}\text { 3. Did the adverse reaction improve } \\
\text { when the drug was discontinued or a } \\
\text { specific antagonist was given? }\end{array}$ & +1 & & \\
\hline $\begin{array}{l}\text { 4. Did the adverse reaction appear } \\
\text { when the drug was re-administered? }\end{array}$ & & & 0 \\
\hline $\begin{array}{l}\text { 5. Are there alternative causes that } \\
\text { could have caused the reaction? }\end{array}$ & 1 & & \\
\hline $\begin{array}{l}\text { 6. Did the reaction reappear when a } \\
\text { placebo was given? }\end{array}$ & & & 0 \\
\hline $\begin{array}{l}\text { 7. Was the drug detected in any body } \\
\text { fluid in toxic concentrations? }\end{array}$ & & 0 & \\
\hline $\begin{array}{l}\text { 8. Was the reaction more severe when } \\
\text { the dose was increased, or less severe } \\
\text { when the dose was decreased? }\end{array}$ & +1 & & \\
\hline $\begin{array}{l}\text { 9. Did the patient have a similar } \\
\text { reaction to the same or similar drugs in } \\
\text { any previous exposure? }\end{array}$ & & 0 & \\
\hline $\begin{array}{l}\text { 10. Was the adverse event confirmed } \\
\text { by any objective evidence? }\end{array}$ & +1 & & \\
\hline Total Points & +8 & & \\
\hline
\end{tabular}

*Note that a score between 5-8 is seen as a "probable adverse drug reaction" while 9 or greater is defined as "definite adverse drug reaction" [29].

Table 3: Naranjo scale revealing probable adverse drug reaction. 
(>90\%) with high volumes of distribution (> $2 \mathrm{~L} / \mathrm{kg}$ ) [8]. Therefore, treatment is largely supportive. Little data exists on the efficacy of different management options. If the patient is stable, orogastric lavage may be helpful, especially if CCBs were ingested within one hour of presentation [8]. In patients who are more unstable, profound bradycardia should be initially treated with atropine, similar to other Advanced Cardiac Life Support patients [31]. If there is no improvement, transcutaneous or transvenous cardiac pacing can then be employed [8]. If cardiac output and perfusion pressure are not improved calcium chloride or calcium gluconate can be administered, which can lead to small improvements in conduction, inotropy, and blood pressure. These measures may not be sufficient, which may eventually require the addition of vasopressors [8].

In a few reports, the addition of high-dose insulin therapy (110 units $/ \mathrm{kg}$ ) with concurrent glucose administration (to maintain eugylcemia) has been shown to be more effective than solely using calcium, epinephrine, or glucagon $[17,32,33]$. Since verapamil decreases the uptake of fatty acids in myocytes and decreases insulin secretion from pancreatic islet cells [17], the addition of insulin may lead to improved cardiac contractility and intact peripheral resistance, probably because insulin triggers cells to rely on carbohydrate rather than fatty acid metabolism $[8,33]$. Insulin may also have intrinsic inotropic properties through unknown mechanisms [17]. In a case series of five patients in circulatory shock due to verapamil or amlodipine overdose, high-dose insulin and dextrose infusions showed restoration of hemodynamic status [32]. This approach has led to few side effects, provided that serum glucose levels are frequently checked.

Also, CCB toxicity can be treated with intravenous lipid emulsion (ILE) infusion. ILE infusion was first used to treat local anesthetic systemic toxicity [34], but can also benefit patients with other lipophilic drug toxicities, including tricyclic anti-depressants, beta blockers, and calcium channel blockers. In animals, ILE has been shown to reverse verapamil toxicity [35], and Young et al. demonstrated ILE's efficacy in a human patient treated with verapamil toxicity [36]. However, more clinical evidence is needed before ILE becomes a first line agent for non local anesthetic lipophilic toxicity.

In cirrhotic patients, renal replacement therapy may theoretically be beneficial in removing non-protein bound verapamil. Although verapamil is a highly protein bound medication, cirrhotics have lowprotein levels, that may lead to a significant amount of unbound verapamil, which may be more easily dialyzable by standard renal replacement therapy. However, the results of studies assessing verapamil pharmacokinetics in renal failure and drug removal by hemodialysis vary, making it difficult to recommend hemodialysis [3739]. Furthermore, this mechanism of action may be unlikely, as the drug percentage that is bound has been found to remain unchanged in previous pharmacokinetic studies with cirrhotic patients [40]. Also, the large volume of distribution in patients with cirrhosis makes it further unlikely to be dialyzable [26].

In patients with liver disease who also have renal failure in the setting of acute or chronic liver failure, dialysis techniques to remove hydro soluble and non-hydro soluble substances from plasma can have significant benefits. One system, the molecular adsorbent recirculating system (MARS), has been shown to remove a variety of endogenous substances and albumin-bound toxins from blood, including bilirubin and ammonia [41]. Alternatively, albumin dialysis techniques have also been shown to clear benzodiazepines and derivative substances, improve systemic hemodynamic, and resolve hepatic encephalopathy quicker versus standard methods [41,42]. Either of these systems are worth considering, since both are able to manage the sequel of liver failure (e.g. rising ammonia levels, hemodynamic issues), in addition to clearing highly protein-bound medications.

\section{Conclusion}

Case reports and animal experiments have supported the use of intravenous fluids, calcium, vasopressors, high-dose insulin, glucagon, catecholamine, intravenous lipid emulsions and albumin dialysis techniques in patients with CCB toxicity. Given the critical condition of patients and the lack of data supporting the use of any single therapy, a combination of these management strategies is often employed, as evident in this case. In patients with cirrhosis, a similar strategy should be implemented. However, extra care should be taken because many patients with liver disease many have underlying compromise to their circulatory system. Finally, this patient's presentation emphasizes the need for caution in prescribing calcium channel blockers, such as verapamil, to patients with cirrhosis since hepatic clearance can be impaired and result in adverse events.

\section{References}

1. Chobanian AV, Bakris GL, Black HR, Cushman WC, Green LA, et al. (2003) The seventh report of the joint national committee on prevention, detection, evaluation, and treatment of high blood pressure: the JNC 7 report. JAMA 289: 2560-2572.

2. Abrams J (2005) Clinical practice. Chronic stable angina. N Eng J Med 352 2524-2533.

3. Akhtar M, Tchou P, Jazayeri M (1989) Use of calcium channel entry blockers in the treatment of cardiac arrhythmias. Circulation 80: IV31-39.

4. Anderson JL, Adams CD, Antman EM, Bridges CR, Califf RM, et al. (2011) 2011 ACCF/AHA Focused Update Incorporated Into the ACC/AHA 2007 Guidelines for the Management of Patients With Unstable Angina/Non-STElevation Myocardial Infarction: A Report of the American College of Cardiology Foundation/American Heart Association Task Force on Practice Guidelines. Circulation 123: e426-579.

5. Antman EM, Anbe DT, Armstrong PW, Bates ER, Green LA, et al. (2004) ACC/AHA Guidelines for the Management of Patients With ST-Elevation Myocardial Infarction - Executive Summary: A Report of the American College of Cardiology/American Heart Association Task Force on Practice Guidelines (Writing Committee to Revise the 1999 Guidelines for the Management of Patients With Acute Myocardial Infarction). Circulation 110: 588-636.

6. Aronow WS, Fleg JL, Pepine CJ, Artinian NT, Bakris G, et al. (2011) ACCF/AHA 2011 Expert Consensus Document on Hypertension in the Elderly: A Report of the American College of Cardiology Foundation Task Force on Clinical Expert Consensus Documents. Circulation 123: 2434-2506.

7. DeWitt CR, Waksman JC (2004) Pharmacology, pathophysiology and management of calcium channel blocker and beta-blocker toxicity. Toxicol Rev 23: 223-238.

8. Newton CR, Delgado JH, Gomez HF (2002) Calcium and beta recepto antagonist overdose: a review and update of pharmacological principles and management. Semin Respir Crit Care Med 23: 19-25.

9. Wiesner R, Edwards E, Freeman R, Harper A, Kim R, et al. (2003) Model for end-stage liver disease (MELD) and allocation of donor livers. Gastroenterology 124: 91-96.

10. Richard AL, Hantson P (2010) Cardiocirculatory collapse after a single dose of sustained-release verapamil in a cirrhotic patient: usefulness of hyperinsulinaemia-euglycaemia therapy. Anaesth Intensive Care 28: 398-400.

11. Sakurai H, Kei M, Matsubara K, Yokouchi K, Hattori K, et al. (2000) Cardiogenic shock triggered by verapamil and atenolol: a case report of therapeutic experience with intravenous calcium. Jpn Circ 64: 893-896.

12. Stehle G, Buss J, Eibach J, Plügge T, Lasserre JJ, et al. (1990) Cardiogenic shock associated with verapamil in a patient with liver cirrhosis. Lancet 336 1079

13. Ramoska EA, Spiller HA, Myers A (1990) Calcium channel blocker toxicity. Ann Emerg Med 19: 649-653. 
Citation: Galiatsatos P, Johnson D, Childers RE, Demazumder D, Zakaria S (2013) Calcium Channel Blocker Toxicity in a Cirrhotic Patient. Cardiol Pharmacol 2: 106. doi:10.4172/2329-6607.1000106

Page 5 of 5

14. Proano L, Chiang WK, Wang RY (1995) Calcium channel blocker overdose. Am J Emerg Med 13: 444-450.

15. Wax PM (1995) Intestinal infarction due to nifedipine overdose. J Toxicol Clin Toxicol 33: 725-728.

16. Verbrugge LB, Van Wezel HB (2007) Pathophysiology of verapamil overdose: new insights in the role of insulin. J Cardiothorac Vasc Anesth 21: 406-409.

17. Kline JA, Leonova E, Raymond RM (1995) Beneficial myocardial metabolic effects of insulin during verapamil toxicity in the anesthetized canine. Crit Care Med 23: 1251-1263.

18. Groszmann RJ (1994) Hyperdynamic circulation of liver disease 40 years later: pathophysiology and clinical consequences. Hepatology 20: 1359-1363.

19. Garcia-Tsao G, Bosch J (2010) Management of varices and variceal hemorrhage in cirrhosis. N Eng J Med 362: 823-832.

20. Al-Hamoudi WK (2010) Cardiovascular changes in cirrhosis: Pathogenesis and clinical implications. Saudi J Gastroenterol 16: 145-153.

21. Moller S, Henriksen JH (2008) Cardiovascular complications of cirrhosis. Gut 57: 268-278.

22. Wong F, Girgrah N, Graba J Allidina Y, Liu P, et al. (2001) The cardiac response to exercise in cirrhosis. Gut 49: 268-275.

23. Marik PE, Gayowski T, Starzl TE (2005) The hepatoadrenal syndrome: A common yet unrecognized clinical condition. Crit Care Med 33: 1254-1259.

24. Tayek JA (2005) Lower cortisol concentrations in patients with liver disease: More adrenal failure or more confusion? Crit Care Med 33: 1431-1432.

25. Lexi-Comp Online ${ }^{T M}$, Lexi-Drugs Online ${ }^{T M}$, Hudson, Ohio: Lexi-Comp, Inc.

26. Neal EA, Meffin PJ, Gregory PB, Blaschke TF (1979) Enhanced bioavailability and decreased clearance of analgesics in patients with cirrhosis. Gastroenterology 77: 96-102.

27. Somogyi A, Albrecht M, Kliems G, Schäfer K, Eichelbaum M (1981) Pharmacokinetics, bioavailability and ECG response of verapamil in patients with liver cirrhosis. Br J Clin Pharmac 12: 51-60.

28. Verapamil Hydrochloride Tablets USP Revised: May 2012 Rx only 174388-1.

29. Naranjo CA, Busto U, Sellers EM, Sandor P, Ruiz I, et al. (1981) A method for estimating the probability of adverse drug reactions. Clin Pharmacol Ther 30 239-245.
30. Michael EB, Aronoff GR (2007) Drug prescribing in renal failure. 5th edition.

31. Neumar RW, Otto CW, Link MS, Kronick SL, Shuster M, et al. (2010) Part 8 Adult advanced cardiovascular life support: 2010 American Heart Association Guidelines for cardiopulmonary resuscitation and emergency cardiovascular care. Circulation 122: S729-S767.

32. Yuan TH, Kerns WP 2nd, Tomaszewski CA, Ford MD, Kline JA (1999) Insulinglucose as adjunctive therapy for severe calcium channel antagonist poisoning. J Toxicol Clin Toxicol 37: 463-474.

33. Lheureux PE, Zahir S, Gris M, Derrey AS, Penaloza A (2006) Bench-tobedside review: hyperinsulinaemia/euglycaemia therapy in the management of overdose of calcium-channel blockers. Crit Care 10: 212.

34. Weinberg GL (2002) Current concepts in resuscitation of patients with local anesthetic cardiac toxicity. Reg Anesth Pain Med 27: 568-575

35. Tebbutt S, Harvey M, Nicholson T, Cave G (2006) Intralipid prolongs survival in a rat model of verapamil toxicity. Acad Emerg Med 13: 134-139.

36. Young AC, Velez LI, Kleinschmidt KC (2009) Intravenous fat emulsion therapy for intentional sustained-release verapamil overdose. Resuscitation 80: 591 593

37. Storstein L, Larsen A, Midtbo K, Saevareid L (1984) Pharmacokinetics of calcium blockers in patients with renal insufficiency and in geriatric patients. Acta Med Scand 681: 25-30.

38. Mooy J, Schols M, von Baak M, v Hooff M, Muytjens A, et al. (1985) Pharmacokinetics of verapamil in patients with renal failure. Eur $\mathrm{J}$ Clin Pharmacol 28: 405-410.

39. Zachariah PK, Moyer TP, Theobald HM, Frantz RP, Kurtz SB, et al. (1991) The pharmacokinetics of racemic verapamil in patients with impaired renal function. $\mathrm{J}$ Clin Pharmacol 31: 45-53.

40. Sherman RA, Casale P, Cody R, Horton MW (1990) Effect of predialysis verapamil on intradialytic blood pressure in chronic hemodialysis patients. ASAIO Trans 36: 67-69.

41. Gines P, Fernandez J, Durand F, Saliba F (2012) Management of critically-ill cirrhotic patients. J Hepatol 56: S13-S24.

42. Laleman W, Wilmer A, Evenepoel, Elst IV, Zeegers M, et al. (2006) Effect of the molecular adsorbent recirculating system and Prometheus devices on systemic hemodynamics and vasoactive agents in patients with acute-onchronic alcoholic liver failure. Crit Care 10: R108. 